\title{
Proposal for Changing the Korean Terminology of Snoring
}

\author{
Kwang Ik Yang ${ }^{1}$, Ki-Young Jung ${ }^{2}$ \\ ${ }^{1}$ Sleep Disorders Center, Department of Neurology, Soonchunhyang University College of Medicine, Cheonan Hospital, Cheonan, \\ ${ }^{2}$ Department of Neurology, Seoul National University Hospital, Seoul National University College of Medicine, Seoul, Korea
}

\section{Snoring의 국문 용어에 대한 변경 제안*}

양광익 ${ }^{1}$, 정기영 ${ }^{2}$

순천향대학교 의과대학 천안병원 수면장애센터, 신경과학교실, ${ }^{1}$ 서울대학교 의과대학 신경과학교실, 서울대학교병원 신경과 ${ }^{2}$

일반용어도 마찬가지겠지만 의학용어는 질병의 증상, 징 후, 발생기전 등 다양한 의미를 담고 있기 때문에 비영어권 에서 자국의 언어로 번역하는 의학용어 결정은 이런 의미를 이해하는데 있어 매우 중요하다. 영어의 snoring에 대한 한국 말은 '코골이'이다. Snoring에 대한 적절한 우리말 의학용어 를 고찰하기 위해, 여기서는 '코골이'라는 용어 대신에 'snoring'이라는 용어를 사용하겠다.

Snoring은 상기도의 좁아진 부위를 통과하면서 생긴 기압 차 때문에 이완된 연구개와 구개수, 주위 구조물들이 진동하 여 생기는 호흡 잡음이다. ${ }^{1}$ 각성 중의 호흡은 감정, 통증, 대 뇌피질-고위뇌중추에 의한 수의조절 등을 포함한 다양한 외 부자극(wakefulness drive to breath), 동맥혈 산소분압, 이산 화탄소분압 및 산도, 뇌척수액 이산화탄소분압 및 산도가 대 동맥궁에 위치한 말초화학감수체, 연수와 뇌교에 위치한 중 추화학감수체에 전달되고, 이를 호흡관련 근육에 작용하여 폐에서 적절하게 날숨과 들숨(환기)이 이루어진다. 깨어 있을 때는 이런 다양한 자극이 호흡조절 기전을 자극하여 호흡이 일어나지만, 잠이 들면 오로지 화학조절기전에 의해서만 호

\section{Received April 9, 2021 / Accepted April 19, 2021}

\section{Address for correspondence}

Ki-Young Jung, MD, PhD, Department of Neurology, Seoul National University Hospital, Seoul National University College of Medicine, 101 Daehak-ro, Jongno-gu, Seoul 03080, Korea

Tel: +82-2-2072-4988, Fax: +82-2-2072-2474, E-mail: jungky@snu.ac.kr

*논문의 상당 부분은 저자들의 저작인 "양광익. 수면관련호흡장애. In: 증례로 배우는 수면장애. 서울: 범문에듀케이션; 2020. p.149-195”에서 인용하였으며, 범문에듀케이션의 허락을 받았음을 밝힙니다.

This is an Open Access article distributed under the terms of the Creative Commons Attribution Non-Commercial License (https://creativecommons.org/licenses/by-nc/4.0) which permits unrestricted non-commercial use, distribution, and reproduction in any medium, provided the original work is properly cited.
흡이 이루어진다. 또한 수면 중에는 상기도 저항 증가, 폐부 피와 폐흥곽의 순응도 감소를 보이기 때문에 수면 중에는 호 흡 조절이 취약하게 된다. ${ }^{2}$

상기도는 두경부의 골격구조안에서 코부터 성대까지 이어 지는 공기 통로로서, 코의 연골을 제외하고는 그 이하 부위 는 연구개, 목젖, 목구멍기둥, 혀-인두벽 등 좁아지기 쉬운 부드러운 조직으로 구성되어 있다. 안정적인 상기도 개방은 머리-얼굴구조, 상기도 주변 조직, 상기도 자체 특성 및 상기 도 근육을 지배하는 신경-근조절에 의해 유지된다. 깨어 있 을 때는 호흡에 문제가 없다가 수면 중에 상기도 유지가 불 안정해지는 것은, 각성 중 다양한 자극이 호흡 조절에 매우 중요함을 시사한다. ${ }^{3}$

Snoring이 코골이로 표현하는 것이 적절하지 않은 이유는 다음과 같다. 첫째, snoring은 수면 중에만 발생하는 현상이 다. 수면-각성조절은 뇌의 수면 및 각정 조절 센터의 정교한 작용에 의해서 발생하고 유지된다. 잠이 들면 호흡은 화학조 절기전 모드로 전환되고, 이로 인하여 상기도 유지가 불안정 해지게 되고, 상기도 저항이 증가하여 임계폐쇄압력(critical closing pressure, Pcrit)이 상기도 개방력보다 크게 되면 snoring이 발생한다. ${ }^{4}$ 그러므로 snoring은 수면 중 호흡관련 화학 조절기전 및 상기도 개방 유지 기전의 기능 저하로 발생하는 것이다. 아무리 심한 비만이라도 깨어 있을 때는 snoring 현 상이 발생하지 않는다. 둘째, snoring은 잠자는 동안 목구멍 에서 성대까지 이루어져 있는 상기도 구조물 중 연골 이외의 연조직, 예를 들어 연구개, 목젖, 목구멍기둥, 혀-인두벽 등에 저항이 증가하여 소용돌이가 발생하고, 이로 인한 진동에 의 해 발생하는 현상이다. 즉, 코 안의 공간(비강)에서 떨림이나 
울림만으로 소리가 발생하는 것이 아니다. 셋째, 상기도 개방 은 머리-얼굴구조, 상기도 주변 조직, 상기도 자체 특성 및 상기도 근육을 지배하는 신경근조절에 의해 유지된다. 수면 중 적절한 호흡을 유지하기 위해서는 상기도를 이루는 해부 학적 요소 외에 뇌-신경-상기도 근육간 적절한 상호작용이 이루어져야 하는데 그렇지 못한 경우 snoring 및 폐쇄수면무 호흡이 발생한다.

우리는 오랫동안 관습적으로 snoring의 한글 용어로 '코골 이'를 사용해 왔다. 이는 snoring이 코에서 나는 소리라는 인 식에서 나온 잘못된 용어(misnomer)라 할 수 있다. 위에서 살펴보았듯이, snoring은 코에서 발생하는 소리가 아니며, 단 순히 코를 치료한다고 사라지지 않는다. 따라서, snoring에 대한 용어를 ‘코골이' 대신에 '(수면)숨골이'로 대체할 것을 제 안한다. 수면에 괄호를 넣은 것은 수면숨골이가 더 정확하겠 으나, 수면 중에만 발생하는 현상이므로 생략하고 숨골이로 단축하여 부를 수도 있다는 의미이다. Snoring은 수면중에 공기의 흐름을 유지하는 상기도를 조절하는 뇌-신경-근 기 능이 저하되어 상기도의 저항 증가로 인한 호흡 또는 숨의 진 동으로 인한 소리로서, 수면호흡조절 중추가 뇌라는 점을 고 려하면 '(수면)숨골이'라는 용어가 발생기전을 정확히 반영 하는 과학적인 용어이다.

질병의 발생기전이 규명되고 임상양상이 체계화되어 가면 서 질병 분류도 지속적으로 새로운 버전으로 최신화 되듯이, 의학용어 역시 마찬가지로 수정 보안되어야 한다. 사회발전 에 따른 인식 변화와 마찬가지로 의학발전에 따라 새로운 용어 출현과 함께 기존 용어도 새롭게 개편되곤 한다. Snoring의 의학적 발생기전을 고려한다면 '(수면)숨골이'라는 용 어가 정확하고 합리적이다.

\section{Acknowledgments}

\section{Conflicts of Interest}

The authors have no potential conflicts of interest to disclose.

\section{ORCID iDs}

\author{
Kwang Ik Yang \\ https://orcid.org/0000-0001-6343-6520 \\ Ki-Young Jung \\ https://orcid.org/0000-0001-5528-9081
}

\section{Author Contributions}

Conceptualization: Kwang Ik Yang, Ki-Young Jung. Data curation: Kwang Ik Yang, Ki-Young Jung. Formal analysis: Kwang Ik Yang, Ki-Young Jung. Funding acquisition: Kwang Ik Yang, Ki-Young Jung. Investigation: Kwang Ik Yang, Ki-Young Jung. Methodology: Kwang Ik Yang, Ki-Young Jung. Project administration: Kwang Ik Yang, Ki-Young Jung. Resources: Kwang Ik Yang, Ki-Young Jung. Software: Kwang Ik Yang, Ki-Young Jung. Supervision: Kwang Ik Yang, Ki-Young Jung. Validation: Kwang Ik Yang, Ki-Young Jung. Visualization: Kwang Ik Yang, Ki-Young Jung. Writingoriginal draft: Kwang Ik Yang, Ki-Young Jung. Writing_review \& editing: Kwang Ik Yang, Ki-Young Jung.

\section{REFERENCES}

1. Kim SW, Kim HJ. Classification of sleep breathing disorders and definition of respiratory events. In: Korean Rhinologic Society. Snoring and sleep apnea. Seoul: iMiS Company, 2016;15-19.

2. Horner RL. Respiratory physiology: central neural control of respiratory neurons and motoneurons during sleep. In: Kryger MH, Roth T, Dement WC. Principles and practice of sleep medicine. 6th ed. Philadelphia: Elsevier, 2017;155-166.

3. Hinzer R, Sériès F. Physiology of upper and lower airways. In: Kryger $\mathrm{MH}$, Roth T, Dement WC. Principles and practice of sleep medicine. 6 th ed. Philadelphia: Elsevier, 2017;174-181. https://doi.org/10.1016/B9780-323-24288-2.00017-9.

4. Stoohs R, Gold AR. Snoring and pathologic upper airway resistance syndromes. In: Kryger M, Roth T, Dement WC. Principles and practice of sleep medicine. 6th ed. Philadelphia: Elsevier, 2017;1088-1101. https:// doi.org/10.1016/B978-0-323-24288-2.00112-4.

5. McGinley BM, Schwartz AR, Schneider H, Kirkness JP, Smith PL, Patil SP. Upper airway neuromuscular compensation during sleep is defective in obstructive sleep apnea. J Appl Physiol (1985) 2008;105:197-205. https://doi.org/10.1152/japplphysiol.01214.2007. 